\title{
O reino dos Quadriláteros: uma sequência didática para o ensino de Geometria na Educação Básica
}

The kingdom of Quadrilaterals: a didactic sequence for the teaching of Geometry in Elementary Education

\author{
Luciano Soares Gabriel ${ }^{*}$ \\ Norma Suely Gomes Allevato*
}

\section{Resumo}

O presente trabalho refere-se ao produto educacional resultante de uma pesquisa de Mestrado Profissional concluída junto ao Programa de Pós-Graduação em Ensino de Ciências e Matemática da Universidade Cruzeiro do Sul, São Paulo, SP. A pesquisa teve como objetivo principal compreender como uma sequência didática, apoiada na teoria das situações didáticas, pode contribuir para o ensino de Geometria - Quadriláteros - no Ensino Fundamental II. A elaboração da sequência didática baseou-se em noções da Teoria das Situações Didáticas, de Guy Brousseau. Considerando o que se mostrou nos dados da pesquisa, foi possível verificar que a interação dos alunos com a sequência de atividades realizadas facilitou a compreensão dos conceitos e da classificação dos quadriláteros segundo uma perspectiva hierárquica - que considera a classificação de um conjunto de conceitos de modo que os mais particulares são, muitas vezes, subconjuntos dos mais gerais -, além de estimular o desenvolvimento do pensamento matemático e geométrico através da resolução de problemas que estimularam a utilização das habilidades de observação, formulação, comunicação, argumentação e validação.

Palavras-chave: Educação Matemática. Educação Básica. Ensino de Geometria. Sequência Didática. Quadriláteros.

\section{Abstract}

The present work refers to the educational product resulted from a research of Professional Master's Degree completed with the help of the Graduate Program in Science and Mathematics Teaching of the University of Cruzeiro do Sul. The research had as main objective to understand how a didactic sequence, based on the theory of didactic situations, can contribute to the teaching of Geometry - Quadrilaterals - in Elementary Education II. The elaboration of the didactic sequence was based on the

" Luciano Soares Gabriel, Mestre no Ensino de Ciências e Matemática, Vice-Diretor na Rede Estadual de Ensino do Estado de São Paulo, Escola Estadual "Coronel Marcos Ribeiro". E-mail: lussoga@hotmail.com

* Norma Suely Gomes Allevato, Doutora em Educação Matemática, Docente do Programa de Pós-Graduação no Ensino de Ciências e Matemática da Universidade Cruzeiro do Sul. E-mail: normallev@gmail.com 
notions of the Theory of Didactic Situations, made by Guy Brousseau. Considering what was show in the research results, it was possible to verify that the interaction between the students and the sequence of activities performed made easier for them the comprehension of the concepts and of the classification of the quadrilaterals according to a hierarchical perspective - that considers the classification of a set of concepts in way that the more particular sets are, in your majority, subsets of the more general sets - as well as stimulate the development of mathematical and geometrical thinking by solving problems that stimulate the use of observation, formulation, communication, argumentation and validation skills.

Keywords: Mathematical Education. Elementary Education. Geometry Teaching. Didactic Sequence. Quadrilateral.

\section{Introdução}

Como professor de Matemática do Ensino Básico na rede privada há 13 anos e vice-diretor de uma escola estadual há 9 anos, tenho presenciado a dificuldade dos alunos em aprender Matemática, sobretudo no que se refere a conteúdos geométricos. Seja pelo despreparo de alguns professores para ensinar tais conteúdos, seja pela falta de materiais didáticos pedagógicos de apoio ou pela não familiaridade de alguns docentes com recursos tecnológicos, a Geometria torna-se de difícil compreensão e, até mesmo, sem significado para muitos estudantes.

Diante disso, decidimos trabalhar com esse tema em nossa pesquisa de mestrado (GABRIEL, 2017). Para isso, debruçamo-nos em leituras e estudos que nos ajudassem a compreender como ocorreu e ainda ocorre o ensino da Geometria no Brasil. Percebemos que, depois de uma época de abandono que se configurou durante e após o Movimento da Matemática Moderna, hoje seus conteúdos estão presentes nas escolas brasileiras e as práticas pedagógicas para seu ensino estão recebendo atenção de professores e pesquisadores. Contudo, concluímos que é um ramo da Matemática que ainda carece de mais cuidado no que diz respeito à aprendizagem dos alunos, ao material didático e à formação de professores. E, sendo profissional o mestrado em que estávamos inseridos, estabelecemos como um dos objetivos a construção de um Produto Educacional que atendesse a essas demandas, o qual será apresentado no presente trabalho. 
$\mathrm{Na}$ pesquisa que desenvolvemos, também verificamos os apontamentos relativos à Geometria destacados nos documentos brasileiros de orientações curriculares e consideramos as orientações atuais acerca das possíveis abordagens para seu ensino. Segundo PCN (BRASIL, 1998) ${ }^{1}$, o estudo da Geometria deve ter como ponto de partida a análise de figuras através de observações, manuseios e construções, que permitam elaborar conjecturas e identificar propriedades, ou seja, o documento recomenda estimular o aluno a observar, perceber semelhanças e diferenças e identificar regularidades.

Também encontrarmos nos objetivos indicados na Base Nacional Comum Curricular - BNCC (BRASIL, 2017) sobre o ensino de Geometria, um específico relativo ao conteúdo quadriláteros: "Identificar características dos quadriláteros, classificá-los em relação a lados e a ângulos e reconhecer a inclusão de classes entre eles" (BRASIL, 2017, p. 259).

Por isso, elegemos esse conteúdo para criar uma sequência didática, pois, dentre as inúmeras figuras geométricas, os quadriláteros possuem propriedades envolvendo os seus elementos (lados, ângulos, diagonais, área, perímetro, etc.) que, quando trabalhados adequadamente, permitem os alunos raciocinar indutiva e dedutivamente, formulando e testando conjecturas e generalizações, desenvolvendo, assim, o pensamento geométrico. Notamos, portanto, que o estudo com os Quadriláteros vai ao encontro das recomendações dos PCN (BRASIL,1998) e da BNCC (BRASIL, 2017).

\section{A sequência e a Teoria das Situações Didáticas}

O produto educacional aqui apresentado foi constituído a partir da dissertação intitulada "Contributos de uma Sequência Didática para o Ensino de Quadriláteros: compreensões a partir da Teoria das Situações Didáticas", defendida em 20172. O objetivo da pesquisa foi compreender como uma sequência didática, apoiada na Teoria das Situações Didáticas, pode contribuir

\footnotetext{
1 À época da conclusão da pesquisa - junho de 2017 - este era o documento em vigor.

2 Uma outra versão deste produto, com discussões mais completas sobre o Ensino de Geometria, pode ser encontrada em Gabriel e Allevato (2017)
} 
para o ensino de Geometria - Quadriláteros - no Ensino Fundamental II. Fundamentada na Teoria das Situações Didáticas, de Guy Brousseau, a sequência é composta por atividades que levaram o aluno a construir conhecimento matemático através da adaptação a um meio que produz contradições e desequilíbrios. Segundo Brousseau (2008), o aluno deve ser sempre estimulado a esforçar-se para superar seus limites e, com esforço próprio, construir novos conhecimentos. Para isso, sugere que o estudante passe por cinco etapas diante da resolução de um problema, visando à formação de alunos autônomos, reflexivos, ativos, argumentativos e participantes no processo de ensino e aprendizagem:

$\checkmark$ Etapa de devolução: ato pelo qual o professor cede ao aluno uma parte da responsabilidade pela aprendizagem.

$\checkmark$ Etapa de ação: é aquela na qual o aluno, que se encontra ativamente empenhado na procura da solução de problema, realiza determinadas ações mais imediatas. Caracteriza-se pelo predomínio do aspecto experimental e operacional.

$\checkmark$ Etapa de formulação: o aluno já utiliza na solução do problema estudado, alguns modelos ou esquemas teóricos explícitos, além de mostrar um evidente trabalho com informações teóricas de uma forma bem mais elaborada.

$\checkmark$ Etapa de validação: os alunos tentam convencer os interlocutores da veracidade das afirmações que fizeram, utilizando uma linguagem matemática apropriada (demonstrações).

$\checkmark$ Etapa de institucionalização: 0 professor retoma parte da responsabilidade cedida aos alunos e institucionaliza o saber construído, estabelecendo um caráter mais objetivo e universal para o conhecimento. 


\section{Sequência Didática: O Reino dos Quadriláteros Notáveis.}

1- Na próxima aula, você conhecerá uma fantástica história de um reino encantado, mas, para compreendê-la, precisará rever alguns conceitos matemáticos estudados ao longo da sua vida escolar.

Em casa, faça uma pesquisa sobre:

- $\quad$ Polígonos - O que são? Como são classificados? Qual a diferença entre um polígono regular e um não regular? Qual a diferença entre um polígono convexo e um não convexo?

- Retas paralelas - O que são e onde podemos encontrá-las?

- Ângulo reto - O que é? Traga exemplos de onde podemos encontrá-lo.

2- Atividades

2.1) Classifique as figuras a seguir em polígonos e não polígonos. Identifique os polígonos que são convexos e justifique porque os outros não são.

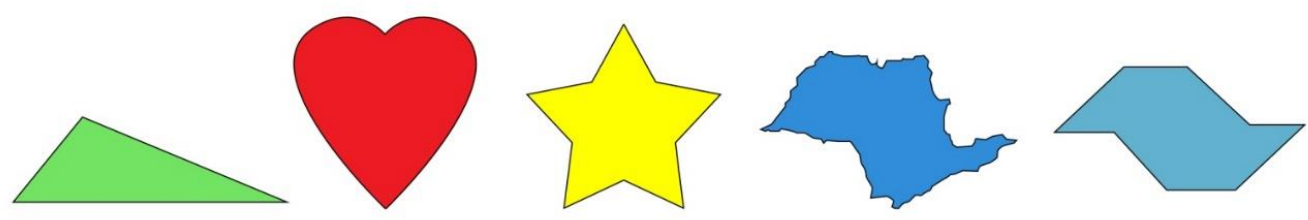

2.2) Complete a tabela de acordo com o número de lados de cada polígono

\begin{tabular}{|l|l|l|}
\hline Polígono & Número de lados & Classificação \\
\hline
\end{tabular}




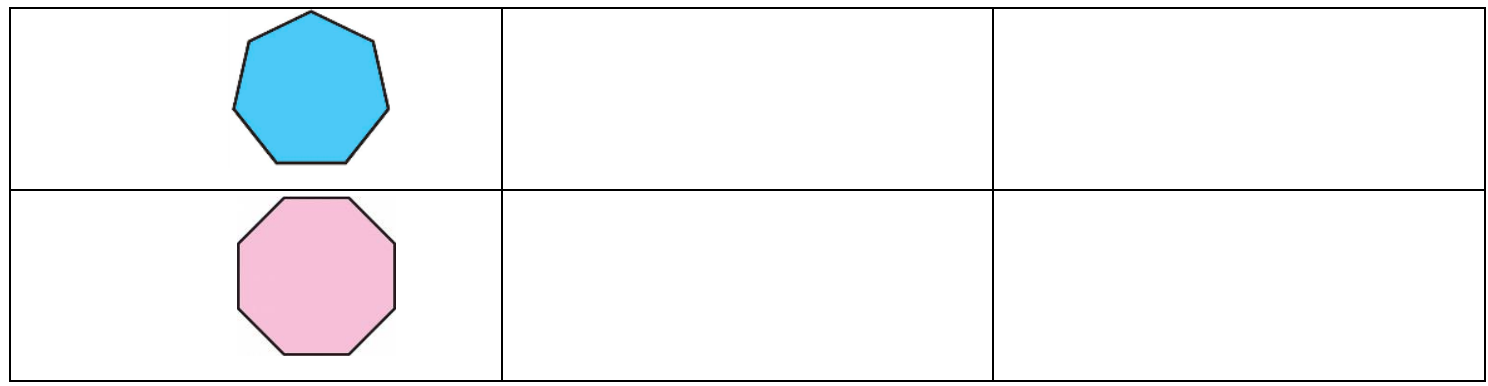

2.3) Na imagem seguinte, identifique: reto.

a) com lápis vermelho, um par de segmentos de reta paralelos e um ângulo

b) com lápis azul, dois polígonos convexos.

c) com lápis verde, um polígono não convexo.

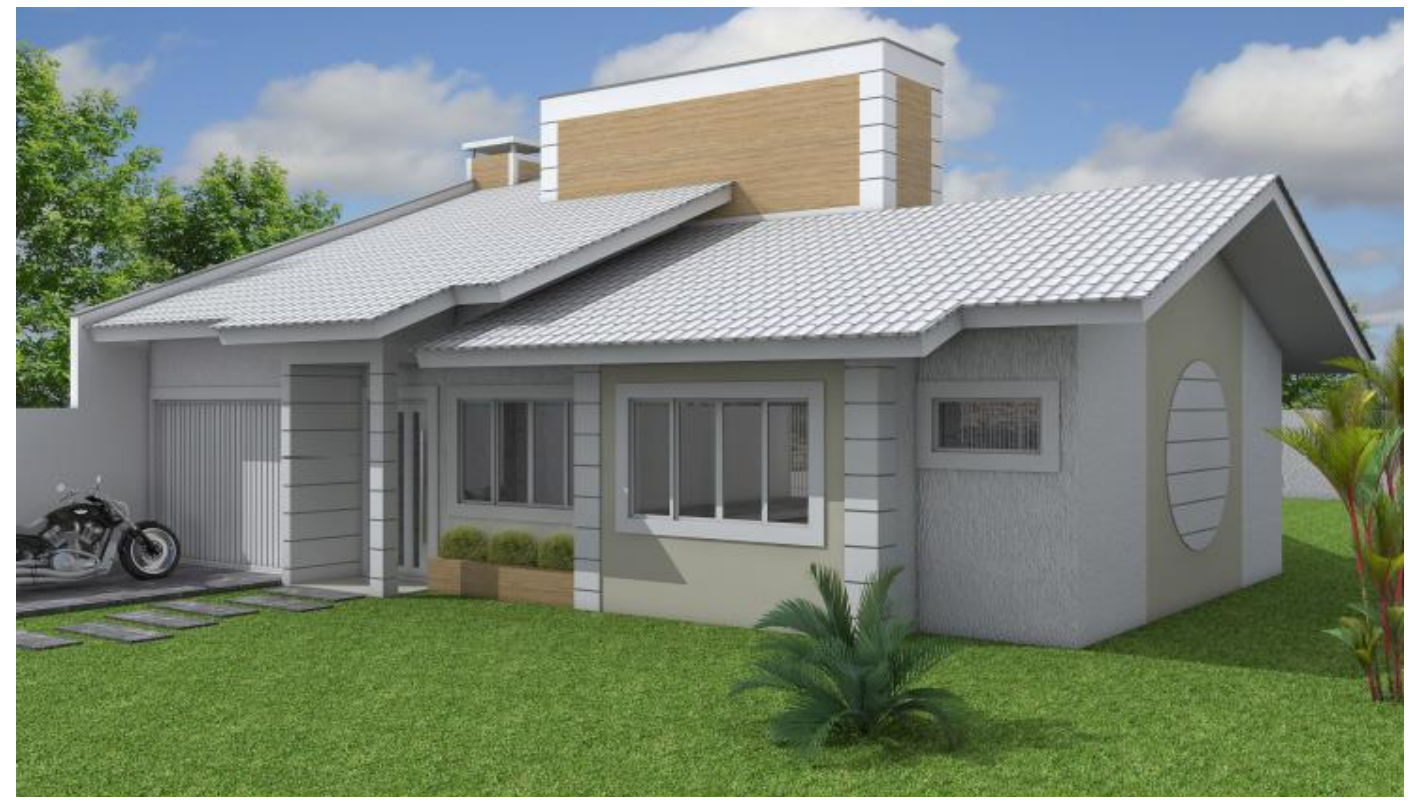

2.4) Depois de realizar as pesquisas, as atividades propostas e de discutir com seu professor e seus colegas de sala, escreva o que você aprendeu após essas aulas.

2.5) Identifique o que você achou mais difícil e explique por quê.

3- As figuras abaixo são quadriláteros e estão distribuídos aleatoriamente. Recorte essas figuras e, em grupo, tente redistribuí-las de acordo com suas características comuns. Por escrito, explique quais foram os critérios que vocês 
utilizaram para construir cada novo grupo de quadriláteros. Escolha um colega do grupo para relatar aos demais alunos da classe os pensamentos do grupo.

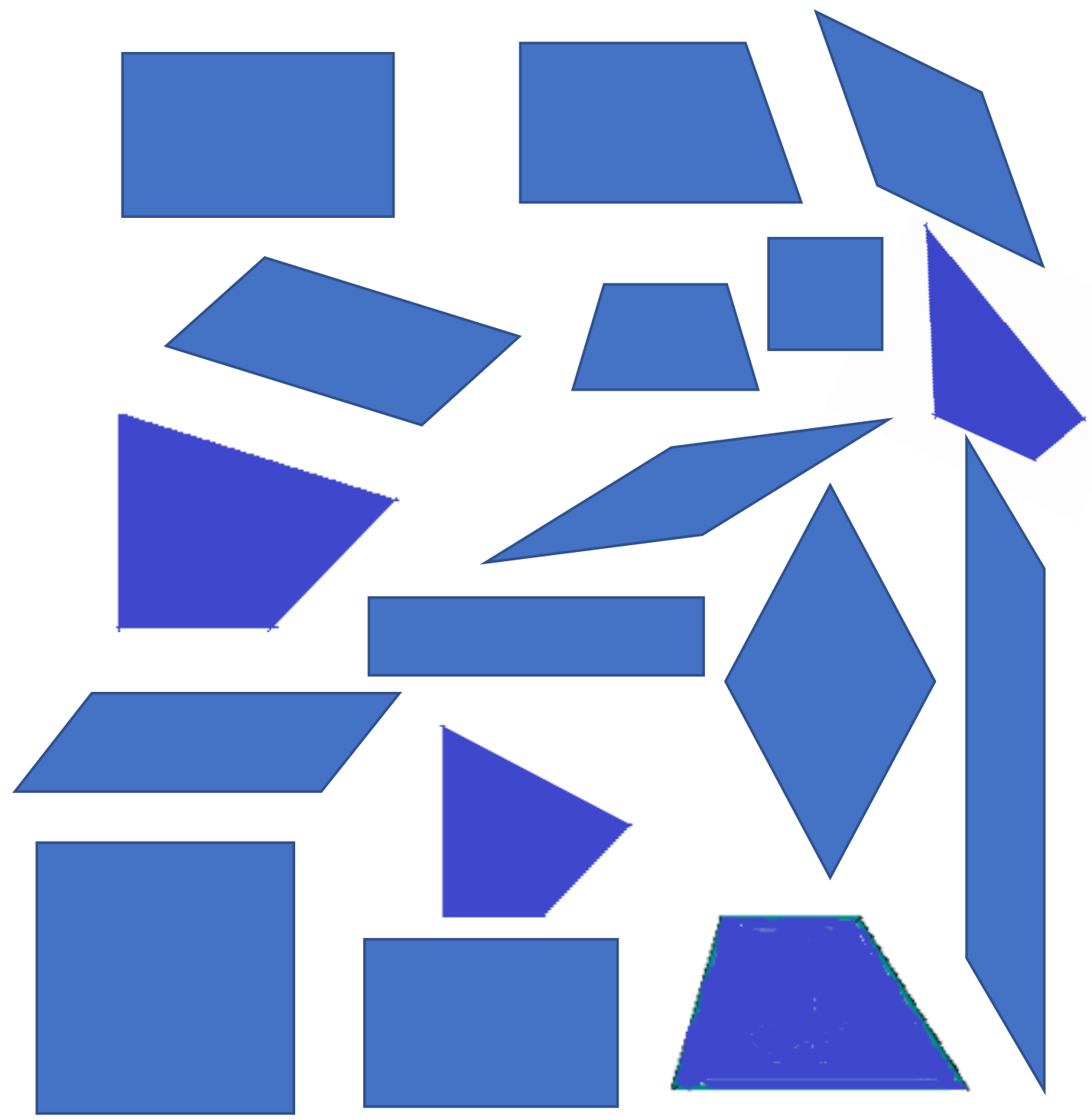

Depois de explanar e discutir os critérios utilizados por seu grupo para classificar os quadriláteros, vocês podem (caso julguem necessário) fazer uma nova classificação, levando em consideração a opinião dos demais colegas de sala.

4- Agora que você já relembrou o que é um polígono, o que é um ângulo reto e o que são retas paralelas, está pronto para conhecer uma divertida história sobre um reino encantado e aprender muito com ela. 


\section{O reino dos Quadriláteros Notáveis}

Há muito tempo, quando os humanos nem pensavam em existir, o mundo era dominado por estranhas criaturas: os polígonos. Tinham poderes mágicos, falavam, movimentavam-se e pensavam.

A luta pelo domínio do planeta era constante entre essas figuras geométricas e, para evitar grandes guerras, eles se dividiam em reinos. Havia o reino dos triângulos, o dos quadriláteros, o dos pentágonos, o dos hexágonos... Mas, frequentemente, aconteciam golpes, através dos quais uns tentavam invadir o reino dos outros em busca do domínio supremo.

$\mathrm{Na}$ tentativa de evitar esses golpes e manter a tranquilidade, os quadriláteros construíram uma grande muralha em torno de seu reino, com apenas uma passagem de acesso, onde um quadrilátero, com fortes poderes, exercia função de guarda.

Qualquer um que ousasse chegar perto da passagem, já de longe escutava os gritos do guarda que assim dizia:

-É um quadrilátero? Tem certeza de que tem quatro lados? Se não tiver, afaste-se, pois algo ruim pode the acontecer.

Assim era resolvido o problema das invasões no reino dos quadriláteros. Contudo, dentro do próprio reino, havia subdivisões. E, como o centro das terras era um lugar fértil e muito bonito, todos queriam lá habitar, porém era impossível, já que o espaço era notoriamente pequeno.

Assim, mais uma vez fortes e poderosos se beneficiavam, ficando com as melhores terras e, com o medo de perderem esse prestígio, novas muralhas eram levantadas e novos guardas foram designados para manter a hierarquia no reino.

A força e o poder dos polígonos de quatro lados eram medidos de acordo com algumas de suas características: lados paralelos thes davam um poder, ângulos retos outros, lados congruentes outros. Existia, portanto, desde quadriláteros sem poderes até outros que acumulavam vários.

A política no reino dos quadriláteros funcionava assim: na muralha mais externa ficava um guarda que só deixava entrar polígonos com quatro lados. 
Perguntava e verificava se o polígono realmente tinha quatro lados. Havendo a confirmação, dava-Ihe um colar com a identificação de quadrilátero.

$\mathrm{Na}$ segunda muralha, interna à primeira, a porta de entrada para terras um pouco mais férteis era vigiada por guardas que faziam uma restrição a mais para quem quisesse entrar. Perguntavam aos quadriláteros se tinham pelo menos um par de lados paralelos e, se tivessem, recebiam um outro colar com identificação de trapézios. Desse modo, nessas terras, entravam os trapézios mais simples (com apenas um par de lados paralelos) e também os paralelogramos, os retângulos, os losangos e os quadrados, que também podiam ser considerados trapézios, já que possuíam a característica exigida pelo guarda.

Para adentrar a área cercada pela terceira muralha, o guarda exigia dois pares de lados paralelos. Os que conseguiam entrar recebiam um colar com a identificação de paralelogramos. Entravam os paralelogramos mais simples (com dois pares de lados paralelos) e também os retângulos, losangos e quadrados, todos acumulando três colares, visto que podiam ser considerados quadriláteros, trapézios e paralelogramos.

A quarta e a quinta muralha se entrelaçavam na região mais rica do reino. A entrega do colar pelo guarda da quarta muralha só acontecia com a condição de que os paralelogramos que lá quisessem entrar tivessem todos os ângulos retos. Já o da quinta muralha, se o paralelogramo tivesse todos os lados iguais.

Na região central (entrelace das quarta e quinta muralhas) também havia guardas e estes não exigiam uma nova característica para liberar a entrada, mas que os pretendentes tivessem todas as características e colares entregues pelos cinco guardas anteriores.

Uns quadriláteros podiam andar por todo o reino, visto que colecionavam todos os colares e tinham todos os poderes; outros somente em algumas regiões (pois possuíam apenas alguns colares) e outros em uma única região.

Durante milhares de anos, os quadriláteros organizaram-se assim até que, um dia, um pentágono irregular conseguiu esconder seu menor lado, passou-se 
por quadrilátero, entrando no reino e destruindo todos os quadriláteros e deixando apenas essa lenda como lembrança do reino.

5- Conhecendo essa história, você pode ajudar os quadriláteros abaixo que perderam seus colares. Vamos considerá-los numerados conforme a seguir:

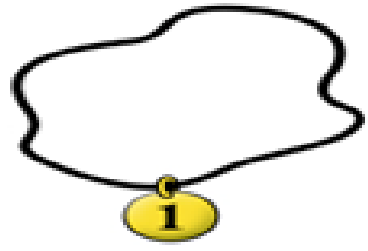

Quadrilátero - possui quatro lados.

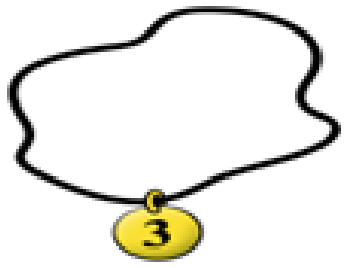

Paralelogramo - possui pelo menos dois pares de lados

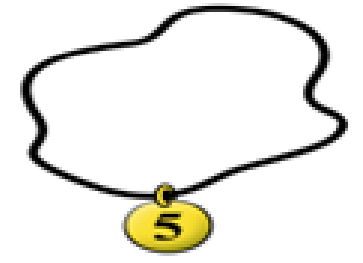

$$
\text { Losango - possui os }
$$

quatro lados iguais.

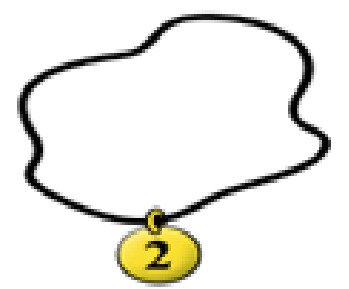

Trapézio - possui pelo menos um par de lados paralelos.

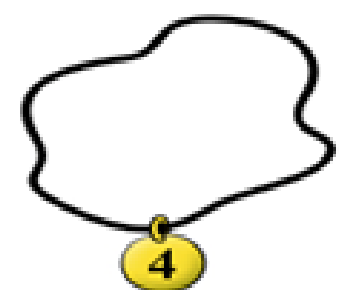

Retângulo - possui os

quatro ângulos retos.

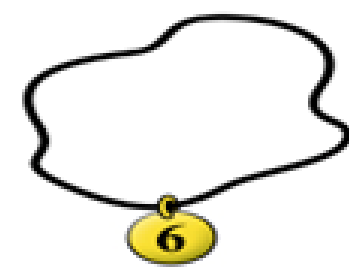

Quadrado - possui as

características de todos os outros

Agora distribua-os de acordo com as características de cada quadrilátero, inserindo o número correspondente a cada colar nas circunferências que estão abaixo de cada quadrilátero a seguir: 


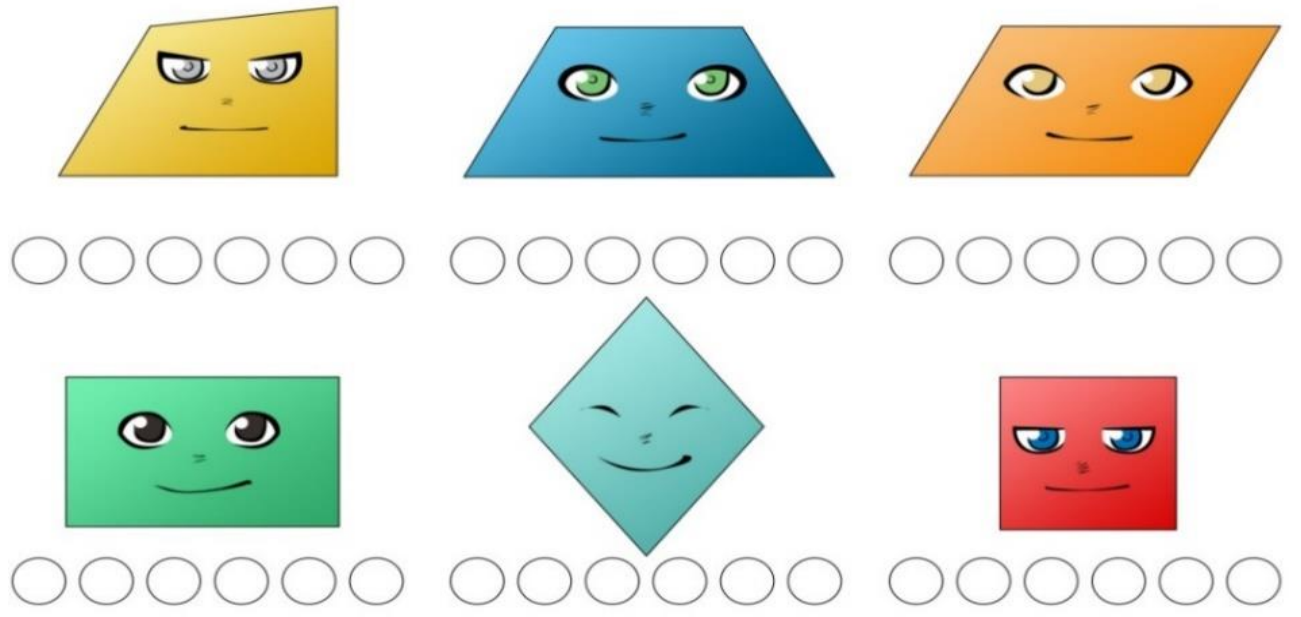

6- A pedido do senhor de todos os polígonos, os quadriláteros tiveram de enviar a planta para mostrar como estava dividido seu reino. Dois quadriláteros ficaram responsáveis por essa tarefa, mas até agora não entregaram: um disse não saber fazer e o outro está quase terminando. Ajude o quadrilátero que disse não saber desenhar seu reino.

7- Para verificar se seu desenho está correto, reúna-se com seu grupo, recorte alguns quadriláteros e distribua-os pelas regiões do reino. Se achar necessário, refaça o desenho.

8- O segundo quadrilátero, responsável por desenhar o reino, acaba de cumprir sua tarefa: desenhou corretamente o reino e suas subdivisões, contudo esqueceu-se de colocar os nomes dos quadriláteros residentes em cada subdivisão. Verifique se o seu desenho confere com o desenho feito pelo quadrilátero e coloque os nomes nas subdivisões que ele esqueceu:

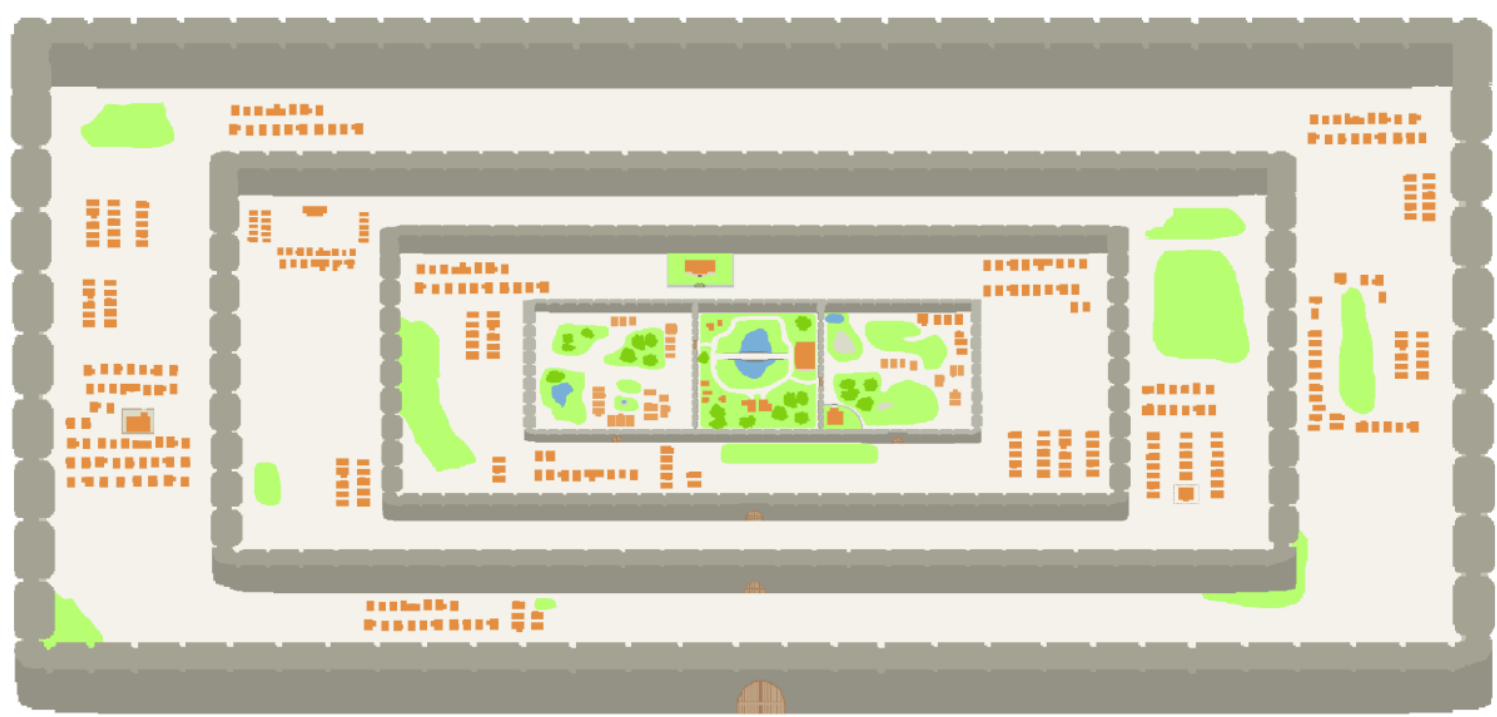


9- Um dia, a tranquilidade do reino foi abalada inesperadamente. Um dos guardas acabou dormindo e alguns quadriláteros entraram em lugares proibidos.

Identifique esses quadriláteros, circulando-os e, com flechas, indique em que lugares deveriam estar.

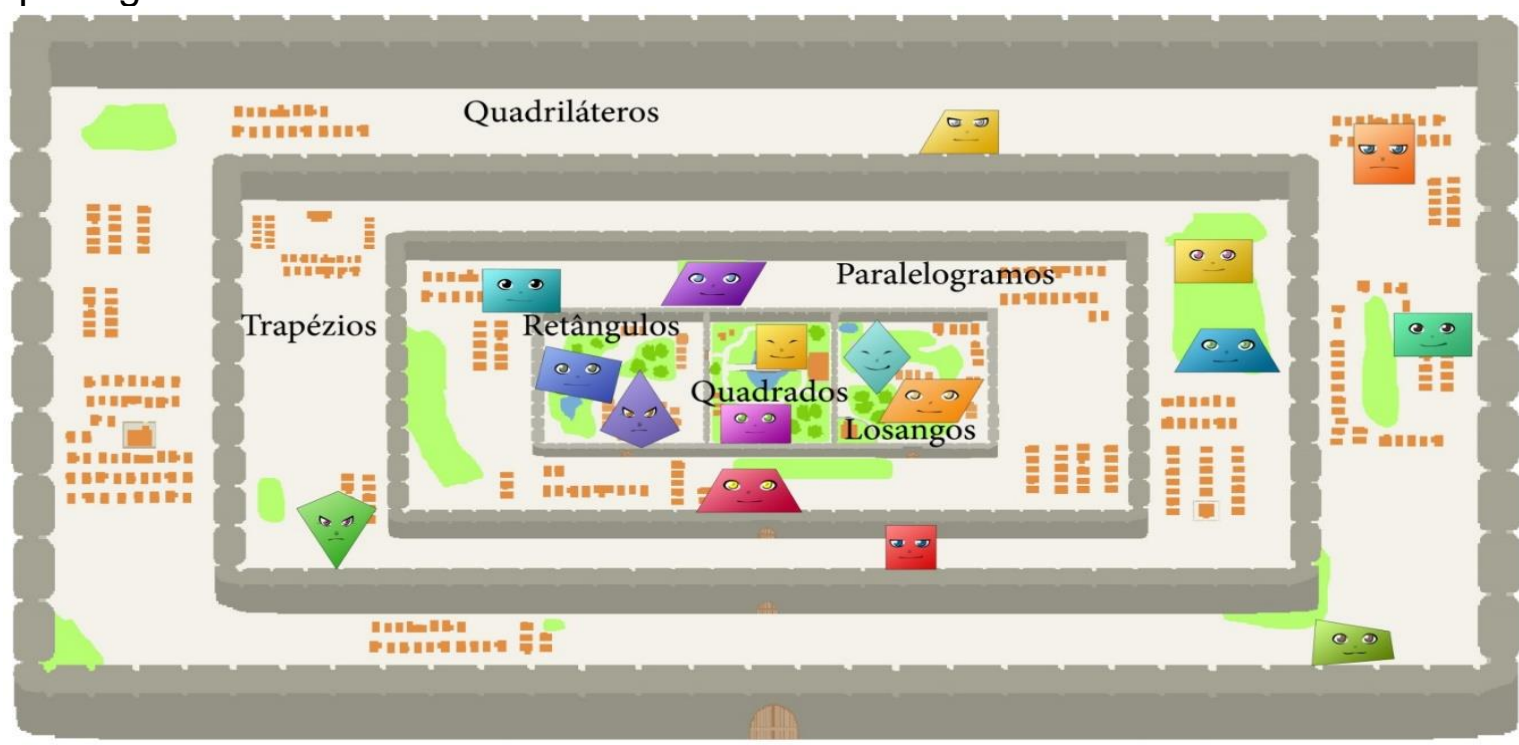

10- Dos quadriláteros abaixo, alguns estão mentindo a respeito de quem realmente são. Identifique os quadriláteros mentirosos e desmascare-os, explicando por que estão mentindo:

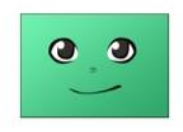

Eu sou um retângulo.

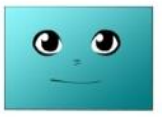

Eu posso ser chamado de paralelogramo.

Eu sou um losango.

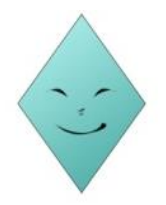

Eu seu um retângulo.

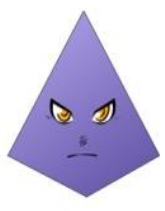

Eu posso ser chamado de trapézio.

ए एu sou um trapézio.

11- Alguns guardas das muralhas estão se aposentando, por isso o reino precisa de novos guardas. Mas, para isso, os quadriláteros precisam passar por uma prova para verificarem se estão aptos a assumirem a função de guardiões.

$\mathrm{Na}$ última prova, um dos quadriláteros, candidato à vaga, reprovou no teste. Como as muralhas não podem ficar sem guardião, uma exceção foi aberta e você, mesmo não sendo um quadrilátero, assumirá a função de guarda. Mas, para isso, precisará passar na prova: 
Nome do candidato:

Idade:

Data:

Prova para exercer a função de guarda do reino dos quadriláteros

1) Classifique as afirmações a seguir como verdadeiras (V) ou falsas (F). Reescreva as falsas, tornando-as verdadeiras.

a) (__ O retângulo também pode ser considerado um trapézio, pois, para ter conseguido essa nomenclatura, já passou pelo guarda dos trapézios.

b) (__ Qualquer paralelogramo pode ser considerado um retângulo, pois possui dois pares de lados paralelos.

c) (__ Os losangos acumulam quatro colares, por isso também podem ser chamados de quadriláteros, trapézios ou paralelogramos. trapézio.

d) (__ Qualquer polígono de quatro lados pode ser considerado um

e) ( $($ ) O quadrado é o quadrilátero mais poderoso, com o maior número de colares, por isso pode ser chamado de trapézio, paralelogramo, retângulo ou losango.

12- Agora que você já é considerado um guardião das muralhas, irá ajudar a formular a próxima prova.

Crie três afirmações a respeito dos quadriláteros: duas verdadeiras e uma falsa. A afirmação falsa precisa ser justificada para servir como gabarito para os corretores da prova.

13- Outro incidente foi um assalto à fábrica de colares do reino. Assim, alguns quadriláteros (ladrões) possuíam colares que não Ihes pertenciam. E como estavam em um período de inverno rigoroso, os polígonos usavam muitas roupas, dificultando a identificação dos quadriláteros por parte dos guardas. Moral da história: muitos quadriláteros que não eram quadrados estavam circulando livremente por todo o reino.

$\mathrm{Na}$ tentativa de prender os bandidos e evitar o constrangimento de pedir para que os quadriláteros tirassem a roupa quando fossem passar pelos portões, criou-se um raio x que, mesmo não sendo capaz de mostrar os lados e os ângulos dos quadriláteros, permitia ver a parte interna dos mesmos, ou seja, suas diagonais.

Com isso, alguns quadriláteros cientistas estão tentando agora estabelecer uma relação entre o tipo de quadrilátero e suas diagonais para que possam 
identificar os ladrões quando esses passarem pelo raio $\mathrm{x}$. Vamos ajudar esses cientistas.

Utilizando três fichas de papel cartão, duas iguais e uma diferente (que representarão as diagonais) e um prendedor para representar o "ponto de encontro" (intersecção) dessas diagonais, ajude os cientistas a identificarem o tipo de quadrilátero pelas suas diagonais.

Reúna-se em grupo com os seus colegas e monte um painel explicando como identificar um quadrilátero pelas suas diagonais. Esse painel será colado ao lado do raio x de cada portão para ajudar os guardas na identificação dos ladrões.

14- Depois de pegarem o certificado de aprovação na prova, os guardas passam por um treinamento: um jogo para aperfeiçoarem suas habilidades de reconhecimento e de classificação dos quadriláteros.

Escolha um colega e vamos para esse treinamento!

Jogo:

Você já sabe que alguns quadriláteros podem movimentar-se por todo o reino e outros não. Para verificar se você realmente entendeu como pode ser realizada essa movimentação, escolha um grupo de quadriláteros (azul ou vermelho) e distribua-os de maneira que cada região fique com pelo menos três quadriláteros. As regras a seguir orientarão sobre a forma de fazer essa distribuição.

- Regras do jogo:

a) Escolha um grupo de quadriláteros (azul ou vermelho).

b) Lance o dado, escolha um dos quadriláteros do seu grupo e movimente0.

c) O número de movimentos pode ser igual ou inferior ao número que caiu no dado, mas nunca superior.

Ganha o jogo aquele que conseguir colocar primeiro, no mínimo, três quadriláteros em cada região do reino. 


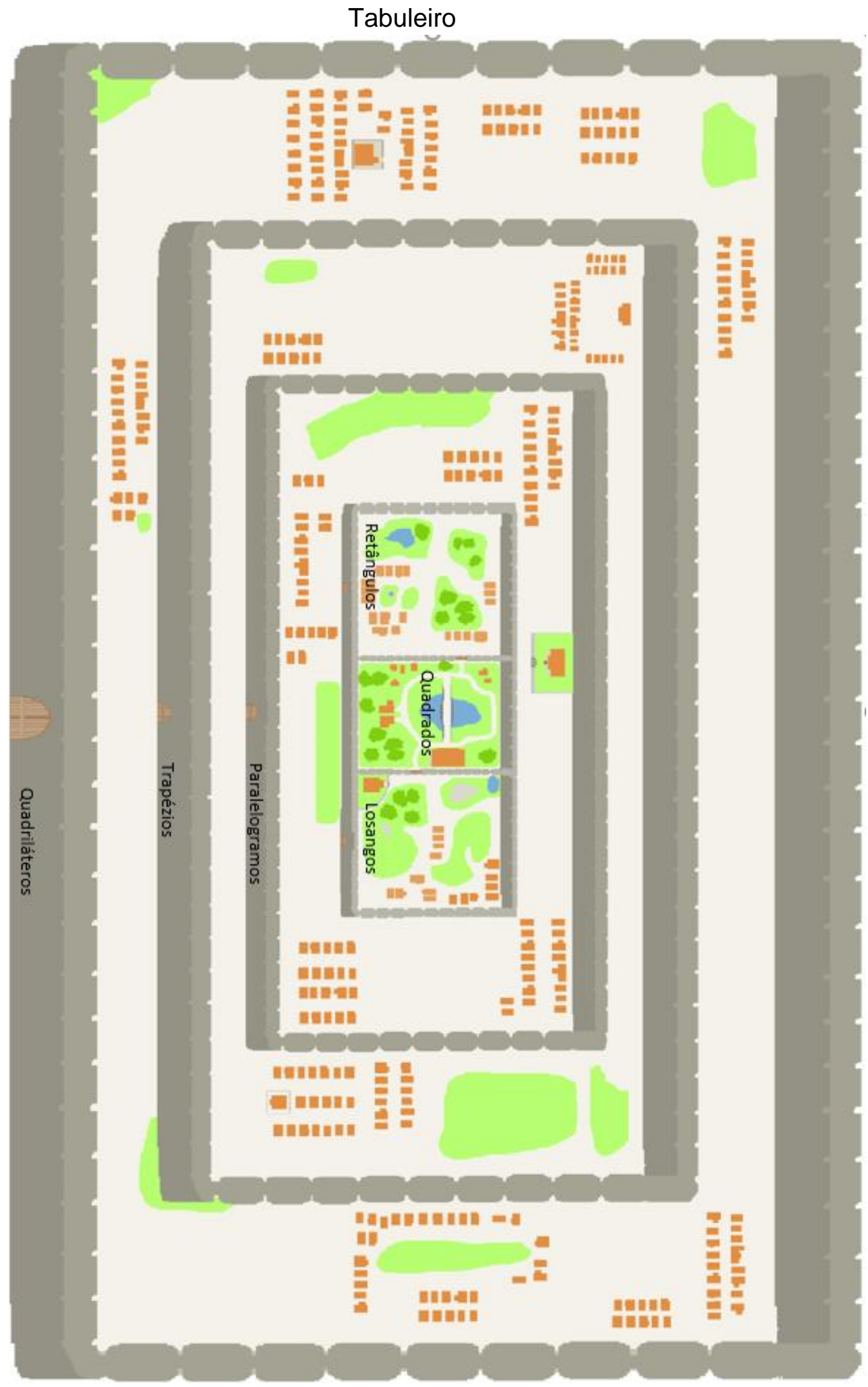


Peças

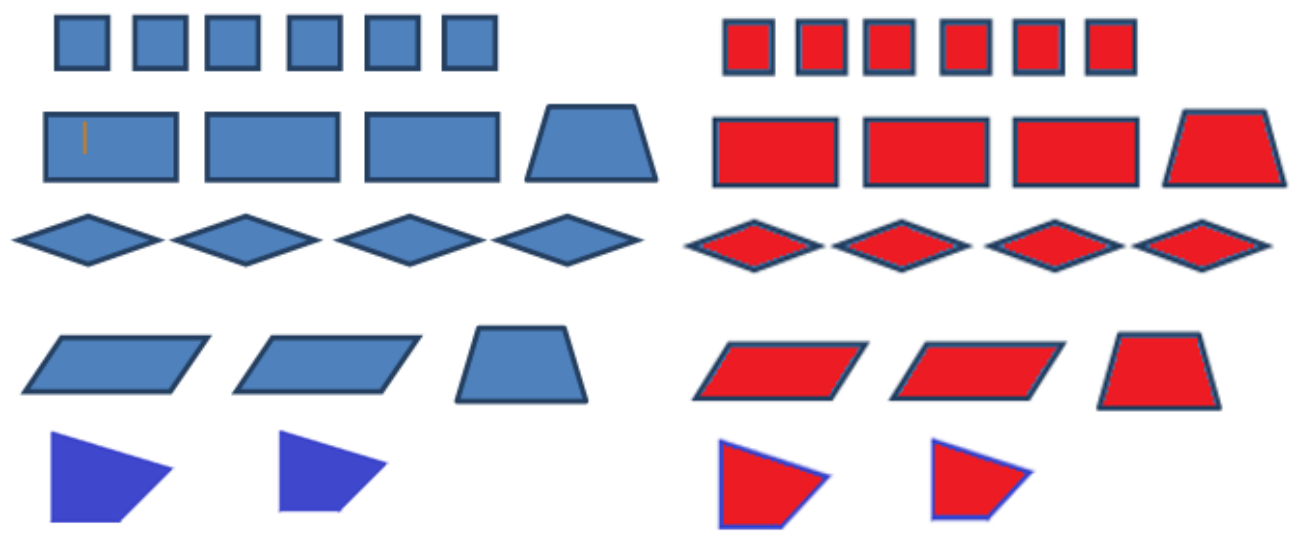

15- Para que nunca mais se esqueça dessa aventura pela qual passou no reino dos quadriláteros, crie um texto relatando tudo o que aprendeu.

\section{Relevância do Produto Educacional}

Antes da seleção e da criação das atividades que comporiam a sequência didática, julgamos adequado investigar o que as pesquisas já realizadas trazem a respeito das diferentes concepções e formas de se abordar um conteúdo de cunho geométrico - Quadriláteros -, bem como as alternativas pedagógicas e didáticas para ensiná-lo. Essas pesquisas podem ser observadas em artigos publicados em periódicos, anais de eventos, dissertações, teses, entre outros meios de divulgação científica.

Observamos que, mesmo com a revalorização da Geometria na Educação Básica, encontramos, em nível de pós-graduação em mestrado e doutorado junto aos programas de Ensino de Ciências e Matemática e Educação Matemática, poucos trabalhos referentes ao conteúdo Quadriláteros. Entre os encontrados, grande parte utiliza o auxílio de algum recurso tecnológico no processo de ensino e aprendizagem que, embora comprovadamente facilite o processo, como demonstram as pesquisas analisadas, infelizmente não é de domínio de muitos docentes e, por isso, acaba sendo pouco utilizado. A falta de políticas públicas 
que capacitem nossos professores ainda é um problema, conforme ressaltam Basztabin et al. (2006):

\begin{abstract}
O que se vê normalmente é a escola apenas investir nos recursos materiais, espaços físicos de laboratórios de informática, TVs, vídeos, DVDs, material de videoconferência, etc. e não investirem na formação continuada dos professores. Com receio de estar perdendo espaço para as máquinas, o professor acaba se estagnando e não se atualizando, o que torna todo o gasto com a infra-estrutura tecnológica um desperdício, pois será utilizada de maneira superficial e sem proveito significativo (BASZTABIN et al., 2006, p. 881).
\end{abstract}

Enquanto a mitificação tecnológica ainda for um obstáculo para os docentes, faz-se necessário, também, investir em pesquisas cuja tecnologia seja acessível à grande maioria deles (professores). Podemos assim, mais uma vez, reforçar os objetivos do nosso trabalho, que é de buscar alternativas pedagógicas, não necessariamente digitais, que auxiliam no desenvolvimento das aulas de Geometria.

\title{
4 Detalhamento e orientações para aplicação do produto educacional
}

Antes de dar início à aplicação da sequência didática, sugerimos, ao professor, uma conversa com os alunos que a vivenciarão, estimulando-os e instigando-os a participarem das atividades. É nesse momento que se estabelece o Contrato Didático e o aluno vivencia a primeira fase de uma situação didática a fase de devolução -, assumindo a responsabilidade pelo conhecimento que se deseja construir.

O tempo previsto para aplicação da sequência é de quinze aulas, podendo variar de acordo com as necessidades e as dificuldades dos alunos durante 0 processo de resolução dos problemas.

Sugerimos que a aplicação das atividades 3 e 13 sejam feitas em aulas duplas, pois, como são atividades pelas quais os alunos vivenciam as cinco fases de uma situação didática, requerem mais tempo para serem realizadas. 
Os processos pelos quais os alunos precisam validar os conhecimentos em construção, no momento de compartilhar e discutir as resoluções elaboradas pelo grupo, podem ser facilitados se o professor scanear as produções dos estudantes e projetá-las na lousa. Isso facilita tanto para os grupos de alunos que precisam expor suas ideias, quanto para os que precisam acompanhar e entender 0 pensamento dos colegas.

Reafirmamos que o professor deverá providenciar uma cópia da sequência didática por aluno e, antes de imprimi-la, deverá fazer algumas adequações referentes à formatação, visto que neste produto educacional as atividades foram colocadas sem os espaços para os alunos resolverem os problemas e com letras menores.

Todo o material utilizado pelos alunos na resolução das atividades deve ser providenciado previamente pelo professor - tesoura, cola, papel sulfite, cartolina, tabuleiro do jugo e dados.

Sugerimos, ainda, que o tabuleiro do jogo seja impresso em papel A3, pois, sendo maior, facilita a movimentação das peças durante as partidas do jogo.

\section{Potencial do produto educacional}

Durante o desenvolvimento da pesquisa que originou o presente produto educacional (GABRIEL, 2017), aprofundamo-nos em estudos sobre as Situações Didáticas, o ensino de Geometria e a classificação dos Quadriláteros. Para colocar em prática as teorias que estudamos, tivemos que avaliar - como pesquisadores - o nosso próprio trabalho como professores. Foram momentos muito ricos, pois nos deram a chance de refletir sobre a importância do conhecimento teórico, por parte dos docentes, ao realizar uma prática pedagógica. Hoje, depois desses estudos, percebemos a importância de abordar, não apenas um conteúdo de cunho geométrico, mas qualquer outro conteúdo matemático, através da dinâmica de resolução de problemas proposta pela Teoria das Situações Didáticas. 
Analisando os apontamentos e descobertas revelados pelos alunos em seus diálogos e registros escritos das resoluções que elaboraram para os problemas, entendemos que a abordagem do conteúdo matemático Quadriláteros - através de uma sequência didática, apoiada na Teoria das Situações Didáticas, contribuiu para o ensino de Geometria. A sequência proporcionou aos alunos refletir, simular processos e realizar tentativas ao se depararem com um problema, formulando, testando e reformulando hipóteses para resolvê-lo. Também oportunizou a realização de elaboração de justificativas para validarem seus raciocínios. Durante o processo de validação vivenciado pelos estudantes em algumas das atividades, desenvolveram habilidades de argumentação e comunicação matemática, aprimorando, assim, seu vocabulário matemático e compartilhando diferentes estratégias de resolução de um problema. Percebemos, ainda, que a troca de experiências proporcionada pelo trabalho em grupos auxiliou os adolescentes a desenvolverem atitudes de colaboração mútua, socialização e interação, aumentando a autoconfiança, a autonomia e fortalecendo o pensamento crítico de cada membro do grupo.

\section{Referências}

BASZTABIN, R.; BORTOLOZZO, A. R. S.; CANTINI, M. C.; FARIA. D. S; FABRÍCIO, F. B. V.; MATOS, E. O desafio do professor frente as novas tecnologias. In: VI EDUCERE CONGRESSO NACIONAL DE EDUCAÇÃO DA PUCPR, 6., 2006. Curitiba/PR. Anais... Curitiba: Champagnat, 2006. p. 876-893.

BRASIL. Ministério da Educação. Base Nacional Comum Curricular: documento preliminar, terceira versão. Brasília: MEC, 2017.

. Ministério da Educação e do Desporto. Secretaria da Educação Fundamental. Parâmetros curriculares nacionais: matemática. 3. ed. Brasília: MEC, 1998.

BROUSSEAU, G. Fundamentos e Métodos da Didáctica da Matemática. In: BRUN, J. Didática das Matemáticas. Tradução de: Maria José Figueiredo. Lisboa: Instituto Piaget, 1996 a. Cap. 1. p. 35-113.

Introdução ao estudo das situações didáticas: conteúdos e métodos de ensino. São Paulo: Ática, 2008. 
http://dx.doi.org/10.5965/2357724X06102018145

GABRIEL, L. S. Contributos de uma Sequência Didática para o Ensino de Quadriláteros: compreensões a partir da Teoria das Situações Didáticas. 2017. 143 f. Dissertação (Mestrado em Ensino de Ciências e Matemática) - Universidade Cruzeiro do Sul, São Paulo, 2017.

GABRIEL, L. S.; ALLEVATO, N. S. G. O Reino dos Quadriláteros: uma sequência didática para o ensino de Geometria na Educação Básica. Produto Educacional. São Paulo: Universidade Cruzeiro do Sul, 2017. Disponível em:

<https://www.cruzeirodosul.edu.br/wp-content/uploads/2018/03/PE-LUCIANO-SOARESGABRIEL-2017.pdf>. Acesso: 24 abr. 2018. 